\title{
Research on Challenges and Strategies for Teacher Professional Development in Minority Areas in the Era of "Internet+"
}

\section{-Survey on the Professional Development of Teachers in a Minority County}

\author{
Wei Li, Jialin Ping \\ School of Education, Chengdu Normal University, Chengdu, China \\ Email: hnlyj1999@126.com
}

How to cite this paper: $\mathrm{Li}, \mathrm{W}$. and Ping, J.L. (2019) Research on Challenges and Strategies for Teacher Professional Development in Minority Areas in the Era of "Internet+". Open Journal of Social Sciences, 7, 60-68.

https://doi.org/10.4236/jss.2019.77006

Received: June 13, 2019

Accepted: July 13, 2019

Published: July 16, 2019

Copyright $\odot 2019$ by author(s) and Scientific Research Publishing Inc. This work is licensed under the Creative Commons Attribution International License (CC BY 4.0).

http://creativecommons.org/licenses/by/4.0/

\begin{abstract}
The "Internet+" era has brought tremendous changes in the roles and functions of teachers, and has put forward new requirements for the professional development of teachers. The professional development of teachers in minority areas bears on the quality of education in ethnic areas. In the era of "Internet+", teachers in minority areas must seize the opportunities brought by the time and respond to the challenges of the time to meet the requirements for professional development in the ethnic areas. Based on the "Internet+" perspective, this study conducts an in-depth analysis of the roles and functions of teachers in the new era, and explores the opportunities and challenges faced by teachers regarding professional development in the "Internet+" era. Through research on the professional development of teachers in a certain ethnic county, the study puts forward the strategies and suggestions for the professional development of teachers in ethnic areas in the era of "Internet+".
\end{abstract}

\section{Keywords}

"Internet+" Era, Professional Development, Strategies

\section{Introduction}

The concept of "Internet+" was first put forward by Chairman of Board of Yi Guan in 2012, and attracted mounting attention, arousing heated discussions. In the era of "Internet+", a series of changes have taken place in the education sys- 
tem. The subject of education and the ways of classroom teaching have undergone tremendous changes. The roles and functions of teachers are constantly changing. Meanwhile, in the era of "Internet+", it has already become a unavoidable issue in the current background of the time that how teachers in ethnic areas can effectively use new technologies to cope with the challenges of the "Internet+" era, so that the technologies and concept of the "Internet+" era can better help them achieve professional development. At the same time, this issue also is of great significance because it bears on the quality of education in ethnic areas in the future. This study surveys the professional development of teachers in a certain ethnic minority county, aiming to better study the influence and strategies of teachers in the professional development under the background of "Internet+", so as to provide better theoretical support for the research of the academic and educational circles on the professional development of teachers in the region.

\section{Changes in the Roles and Functions of Teachers in the Era of "Internet+"}

In the era of "Internet+", the functions that teachers should have are no longer limited to teaching, but tend to be diversified and varied. Teaching also evolves from teaching in front of stage to teaching in front of screen.

\subsection{The Functions of Teachers Are Increasingly Diversified}

In the "Internett" era, the authority of teachers' roles gradually diminishes, teacher's functions are diversified, and teachers are no longer the traditional people standing on the podium. The changes in these functions are mainly reflected in: 1) the innovator of education and teaching; 2) the leaders, helpers, and organizers of students' learning; 3) the promoters of the development of students' thinking ability; 4) the builders and leaders of the harmonious relationship between teachers and students. At the same time, in the "Internet+" era, teachers must also learn to use the resources and materials on the Internet to enrich the teaching design and improve the quality of teaching [1].

\subsection{The Roles of Teachers Shift from Teaching in Front of Stage to Teaching in Front of Screen}

Traditionally, teachers took the three-foot podium to impart knowledge. However, in the "Internett" era, teachers go from in front of stages to in front of computer screens. Compared with the students in the past, the new generation of students influenced by the Internet has desired wider and deeper knowledge, which also makes it difficult for many teachers to fully satisfy the students' needs with their current knowledge reserve. For teachers, how to make better use of the resources of the "Internet+" era and achieve professional development to better meet the knowledge needs of students in front of computer screens is a question that calls for consideration. 


\section{The Analysis of the Opportunities and Challenges Faced by Teachers in the "Internet+" Era}

Based on the previous analysis, we can find that in the "Internet+" era, the functions and roles of teachers have changed, and new demands have been put forward for the professional development of teachers. For teachers, in the era of "Internet+", to achieve their own professional development, they must fully recognize the current opportunities and challenges:

\subsection{Analysis of Opportunities}

The advancement of information and technologies in the era of "Internet+" has provided tremendous opportunities for the professional development of teachers. This is reflected in the following aspects:

1) The sharing of information provides rich resources for teachers' professional development.

In the past, teachers can only seek out-of-school education to improve their own professional quality. In the era of "Internet+", teachers are enabled to break the traditional limitations set by distance. They can obtain new professional knowledge just by connecting to the network and learning on various educational websites or educational platforms. At the same time, on the Internet, teachers can also learn and refer to the classroom teaching methods of other excellent teachers, and have interactions with their peers, which provides resources and methods for the professional development of teachers [2].

2) Network technologies enhance the efficiency of teacher professional development.

In the era of "Internet+", the widespread use of various information technologies has help teachers overcome the limitations of time and space for teacher education and teaching. In the past, teachers can only obtain professional knowledge in certain places to realize professional development. Some knowledge must also be acquired in a certain period of time. In the "Internet+" era, teachers only need a smart phone or tablet to acquire professional knowledge at any time, which greatly enhances the efficiency of teacher professional development.

3) Teacher-student interactions make teachers' professional development more efficient.

The "Internet+" era has also greatly facilitated the interaction between students and teachers [3]. Teachers can not only interact with students in classrooms, but also use various social media in the "Internet+" era to carry out interactions with students after class, so as to get to know the weak points of students' learning and the areas where their teaching needs to be improved. In this way can their professional development be more efficient.

\subsection{Analysis of Challenges}

Although the technologies of the "Internet+" era provide great convenience for the professional development of teachers, they may also cause confusions among 
teachers about professional development if they rely too much on information and technologies. Specifically, the "Internet+" era has brought the following challenges to the professional development of teachers:

1) The sharing of resource may cause teachers to lose their teaching personalities.

In the context of resource sharing in the "Internet+" era, teachers can not only refer to the cases shared by excellent teachers, but also share their own teaching plans and coursewares [4]. However, one of the negative effects of resource sharing is that it may lead to homogenization among teachers. After resources are shared, teachers in different places and at all levels may cite these resources without giving them any modification, thus causing the loss of personalities and creativity of teachers.

2) There is a lack of consideration for the effectiveness of Internet education resources and technologies.

With the arrival of the "Internet+" era, it has become the choice of teachers to use various Internet technologies to enrich the characteristics of teaching and follow trends of the time [5]. However, some teachers deliberately use Internet education resources and information technologies while ignoring the appropriateness of the use of these resources and technologies. They do not fully consider whether the use of technologies can truly enhance their professional abilities and improve the quality of teaching.

\section{Survey on the Professional Development of Teachers in Ethnic Areas in the Era of "Internet+"}

Under the background of "Internett", this study conducted a questionnaire survey of teachers in a certain ethnic county in order to better understand the status quo of teacher professional development in ethnic areas. The purpose of this survey is to learn about the awareness of the professional development of full-time teachers and problems which occur in ethnic areas in the "Internet+" era. To guarantee the validity of the survey, this study distributed questionnaires to 178 full-time teachers in a certain ethnic minority county, and collected 172 questionnaires before the agreed deadline. Among the 172 questionnaires, 2 of them were not completed and thus were considered invalid questionnaires. Therefore, the effective sample rate of this survey is $95.51 \%$.

\subsection{Questionnaire Design}

Based on the previous analysis, in the "Internet+" era, the roles and functions of teachers have changed. At the same time, the "Internet+" era has also brought opportunities and challenges to the professional development of teachers. Therefore, this survey set and divided all the questions into three parts. The first part of the questions aims to find out the understanding of teachers in ethnic areas about the changes of the roles and functions of teachers in the "Internet+" era. These questions include: 1) You are aware that the functions of teachers are 
increasingly diversified. 2) During daily teaching, you often use Internet media and new media to communicate with students besides teaching in front of stage.

The second part of the questions aims to survey how teachers in ethnic areas use the "Internet+" era of information technologies. These questions include: 3) You often download various education resources from the Internet to improve your professional quality. 4) The use of various information technologies and Internet education resources improve the efficiency of your professional development. 5) You often interact with other teachers on online platforms and participate in online education. 6) You often communicate with students through the Internet, understand the shortcomings of your current teaching, and thus plan to improve teaching methods.

The third part of the questions aims to understand the confusion of teachers in ethnic areas about their professional development in the "Internet + " era. These questions include: 7) You often deliberately use information technologies and education resources on the Internet. 8) The use of Internet education resources leads to the gradual homogenization of your teaching with that of your colleagues, thus causing the loss of teaching personality. 9) You often consider the necessity and effectiveness of the use of information technologies and 10) You are often confused about how to choose effective education resources on the Internet.

The Likert scale was introduced into questionnaires when designing answers to all questions. Each answer has five options, namely "completely disagree", "disagree", "neutral opinion", "agree", "completely agree", which corresponds to 1 - 5 points respectively. Then, the questionnaire results were calculated by finding out the average value of each question.

\subsection{Analysis of the Survey Results}

According to the collected statistics of the first part of the questions-1) You are aware that the functions of teachers are increasingly diversified, and 2) During daily teaching, you often use Internet media and new media to communicate with students besides teaching in front of stage, the scores are 4.124 and 4.232 respectively, which is located between "agree" and "completely agree". This demonstrates that teachers in ethnic areas can fully realize the transformation of teachers' roles and functions in the era of "Internet+".

According to the collected statistics of the second part of the questions-3) You often download various education resources from the Internet to improve your professional quality-the average score is 4.754 . The score of the fourth question, 4) The use of various information technologies and Internet education resources improve the efficiency of your professional development, is 4.642, which is located between "agree" and "completely agree". This shows that teachers in ethnic areas often use the education resources of the Internet, and the use of these education resources also enhances the efficiency of their professional development. However, the scores of questions-5) You often interact with oth- 
er teachers on online platforms and participate in online education. 6) You often communicate with students through the Internet, understand the shortcomings of your current teaching, and thus plan to improve teaching methods, are 3.054 and 3.271 respectively, which are located between "neutral opinion" and "agree", and are more likely pointing to "neutral opinion". This shows that teachers in ethnic areas do not make full use of various Internet platforms to interact with other teachers, and participate less in online education on the Internet platform. In addition, teachers in ethnic areas have not used the Internet to interact with students, and have not understood their shortcomings in current teaching from the perspective of students.

According to the collected statistics of the third part of the questions, the scores of the seventh and eighth questions-7) You often deliberately use information technologies and education resources on the Internet. 8) The use of Internet education resources leads to the gradual homogenization of your teaching with that of your colleagues, thus causing the loss of teaching personality, are 4.235 and 4.123 respectively, which are located between "agree" and "completely agree". This result indicates that teachers in ethnic areas often deliberately use information technology and education resources on the Internet, and they also find excessive use of the Internet have deprived themselves of teaching personalities. The score of the ninth question-9) You often consider the necessity and effectiveness of the use of information technologies-is 2.342, which is located between "disagree" and "neutral opinion", and tends to be "disagree". This demonstrates that teachers in ethnic areas rarely consider the necessity and effectiveness of the use of information technologies. The score of the tenth question-10) You are often confused about how to choose effective education resources on the Internet-is 4.324, which indicates that teachers in ethnic areas are often confused about how to choose education resources effectively on the Internet.

\section{Strategies for the Professional Development of Teachers in Ethnic Areas in the Era of "Internet+"}

Under the background of "Internet+", through the survey on the awareness and problems of teacher professional development in ethnic areas, we can find that teachers in ethnic areas have realized that the roles and functions of teachers in the "Internett" era have changed, and they have also used all kinds of education resources on the Internet to improve the efficiency of their professional development. However, the teachers in ethnic areas have still not fully seized the opportunities brought by the "Internet+" era, have not paid attention to the interaction with students, and have not used the online education platform on various Internet platforms to develop their professions. At the same time, teachers in ethnic areas are aware that the deliberate use of information technologies and Internet education resources are making their teaching methods increasingly homogenized and making them lose their teaching personalities, and thus they 
are confused about how to choose effective Internet education resources, without reflecting on the effectiveness and necessity of the use of information technologies. Based on these findings, this paper puts forward the following strategies for the professional development of teachers in ethnic areas in the "Internet+" era.

\subsection{Use Interactive Teaching to Promote Professional Development}

According to the previous survey, we know that teachers in this ethnic area do not pay attention to using the Internet to interact with students, which is also commonly seen in other ethnic areas. This is because many ethnic areas are mostly located in economically underdeveloped areas, and ethnic minority students may use Internet devices less frequently and and can only find less diverse resources compared with their counterparts in economically developed areas. However, with the arrival of the information age, it can be forecast that students from ethnic areas will have access to more Internet devices for learning in the future, which lays a material foundation for the online interaction between teachers and students. Therefore, the author suggests that teachers in ethnic areas should take advantage of the opportunities brought by the "Internet+" era, make full use of interactive teaching to communicate with students effectively and thus learn about their learning situation, as well as students' evaluation of their own teachings. With these efforts, teachers can find flaws in their current teaching and make corresponding improvements to enhance their professional teaching level [6].

\subsection{Use Online Platforms to Promote Professional Development}

According to the previous survey, teachers in ethnic areas have not fully utilized the online platform to share experiences with other teachers on the internet, and they also make less use of online platforms to receive continuing education. Therefore, the author suggests that teachers in ethnic areas should use various online platforms to help promote their professional development, and also realize their professional development through virtual teaching \& research and online education [7]. Specifically, first, teachers in ethnic areas can initiate virtual teaching and research with the help of network technologies, and work to improve their research abilities and level in the application of information technologies. Currently, the advent of blogs and online communities makes it possible for teachers in ethnic areas to absorb excellent ideas and teaching methods, and also contributes to the interaction and exchange of ideas between teachers in ethnic areas, in order to carry out teaching activities in a more effective way and improve professional development. Second, teachers in ethic areas can promote their professional development through the online education platforms. Teachers in ethnic areas also need to actively participate in various online education and vocational continuing education on online platforms in their spare time, so 
that their teaching level and professional knowledge can be improved comprehensively [8].

\subsection{Cultivate the Subject Consciousness of Professional Development and Construct Teaching Content with More Local and Ethnic Characteristics}

According to the previous survey, the sharing of education resources in the era of "Internet + " is causing teachers to lose their own teaching personalities. Subject consciousness is the core of teachers' professional development, and also the key to highlighting the professionalization of teachers. In the context of "Internet+", teachers in ethnic areas should pay attention to constructing the subject consciousness of their own professional development. For instance, when learning and drawing on the teaching experience and teaching methods of excellent teachers in developed regions, teachers in ethnic areas can make corresponding adjustments in light of the reality of minority students, and construct teaching content with more local and ethnic characteristics. The unique culture of ethnic areas can be incorporated into their own teaching, thus enriching the characteristics of their own teaching.

\subsection{Reflect on and Improve the Use of Information Technologies and Online Education Resources}

According to the previous survey, teachers in ethnic areas often deliberately use information technologies and online education resources. Meanwhile, teachers are facing such challenge as how to choose appropriate ones from the excessive education resources on the Internet. Faced with this problem, the author believes that teachers in ethnic areas should integrate what they have learned with real practice, put their knowledge into flexible use and make regular reflection and improvement in the process of professional development with the help of information technologies and online education resources. In practice, reflection and improvement are also essential strategies for the professional development of teachers. In the era of "Internet+", teachers in ethnic areas must first consider whether the use of information technologies can truly improve the quality of teaching and achieve the goal of teaching, rather than blindly follow suit and use various information technologies and online education resources. At the same time, teachers in ethnic areas should also reflect on and evaluate the effect of the use of information technologies and constantly revise the used methods, so as to give full play to the role of information technologies and promote the sustainable development of their professional quality.

\section{Conclusion}

In summary, with the arrival of the "Internet+" era, the roles and functions of teachers are constantly changing, and the technologies and resources of the "Internet+" era also bring opportunities and challenges to the professional development of teachers. Through the survey on teachers in ethnic areas, it can be 
concluded that in the "Internet+" era, teachers in ethnic areas should utilize interactive teaching and online platforms to promote professional development, strengthen the construction of subject consciousness, achieve personalized professional development, and continue to reflect on the use of information technologies and online education resources. With these efforts, teachers can truly promote their professional development and meet the requirements for the professional development of teachers in the "Internet+" era.

\section{Fund Project}

Phased research result of the Research Team of Professional Development of Teachers in Rural Areas in Sichuan, endorsed by Research and Innovation Team of Provincial Universities in Sichuan Province.

\section{Conflicts of Interest}

The authors declare no conflicts of interest regarding the publication of this paper.

\section{References}

[1] Wang, J., Chen, L., Li, X., Xie, F., Yang, J. and Cao, P. (2015) Research on the Teachers' Professional Development in the Frontier Minority Areas from the Respective of TPACK. China Educational Technology, No. 5, 118-123.

[2] Cai, S. (2012) Cultural Dilemma in Professional Development of Ethnic Minority Teachers and Solutions. Journal of Research on Education for Ethnic Minorities, No. 1, 105-109.

[3] Mao, J. (2012) Difficulties and Strategies about Minority Teachers' Professional Development. Journal of Educational Science of Hunan Normal University, No. 4, 32-35.

[4] Yang, S. (2016) The Path of College English Teacher Professional Development in Minority Areas in the "Internet+" Background. Journal of Guangxi Normal University for Nationalities, No. 6, 141-143.

[5] Wang, J. (2016) The Analysis of Teaching Abilities of Young Teachers in Ethnic Colleges in the "Internet+" Background. Minzu Tribune, No. 4, 108-112.

[6] Li, H. (2016) The Exploration of the Directions and Paths of Professional Development of Ideological and Political Teachers in the "Internet+" Background. Education Teaching Forum, No. 28, 26-27.

[7] Shi, J. (2016) The Cultural Consciousness of Professional Development of Ethnic Minority Teachers. Journal of the Chinese Society of Education, No. 8, 96-100.

[8] Wu, L. (2008) Research on Teacher's Profession Development and Insurance Systems in Minorities. Heilongjiang National Series, No. 1, 166-171. 